\title{
Migratory Polyarthritis in the Setting of Chlamydial Infection
}

\author{
Pooja Patel ${ }^{1}$, Hitanshu Dave ${ }^{2}$, Rupak Desai ${ }^{3}$, Priyank J. Yagnik ${ }^{4}$, Elizabeth Davies ${ }^{5}$ \\ 1. Rheumatology, Advocate Aurora Health, Brookfield, USA 2. Internal Medicine, Hackensack Meridian Health - Jersey \\ Shore University Medical Center, Neptune City, USA 3. Cardiology, Atlanta Veterans Affairs Medical Center, Decatur, \\ USA 4. Pediatrics, University of Kansas School of Medicine, Wichita, USA 5. Family Medicine, Prohealth Medical Group, \\ Waukesha, USA
}

Corresponding author: Pooja Patel, pooja5670patel@gmail.com

\begin{abstract}
Reactive arthritis is defined as a sterile inflammation involving the synovial membrane, tendons and/or fascia, elicited by an infection, usually originating from gastrointestinal or genitourinary tracts. Reactive arthritis can also be triggered by a sexually transmitted disease, referred to as sexually acquired reactive arthritis. The most common identifiable cause of non-gonococcal urethritis is Chlamydia trachomatis. Herein, we present a case of a 30 -year-old healthy male patient, who developed migratory oligoarthritis in the setting of elevated inflammatory markers, highlighting the importance of obtaining an appropriate history and ordering pertinent laboratory tests, along with literature review on reactive arthritis.
\end{abstract}

Received 07/01/2019 Review began 07/06/2019 Review ended 07/07/2019 Published 07/24/2019

๑) Copyright 2019 Patel et al. This is an open access article distributed under the terms of the Creative Commons Attribution License CC-BY 3.0., which permits unrestricted use, distribution, and reproduction in any medium, provided the original author and source are credited.
Categories: Internal Medicine, Infectious Disease, Rheumatology

Keywords: migratory, arthritis, oligoarthritis, reactive arthritis, arthralgia, infection, chlamydia trachomatis, case report, polyarthritis, reactive polyarthritis

\section{Introduction}

Reactive arthritis is a rare cause of inflammatory arthritis that occurs following specific genitourinary and gastrointestinal infections: Chlamydia trachomatis and Ureaplasma urealyticum in the urethra and Campylobacter, Escherichia coli, Salmonella, Shigella and Yersinia in the intestine. The term "reactive arthritis" was coined in 1969. It was defined as an "arthritis" that develops during or after an infection elsewhere in the body, but in which a microorganism does not enter the joint cavity [1]. Therefore, the term reactive arthritis was suggested to be more accurate for the entire spectrum of arthritis, triggered by a distant infection (may or may not be detected in the joint) or irrespective of the human leukocyte antigen (HLA)-B27 association [2].

\section{Case Presentation}

A 30-year-old healthy male patient presented to the emergency department with chief concerns of newonset lower extremity and lower back pain. The patient's symptoms began about two weeks ago, with discomforting pain in his left groin that has progressively worsened. The patient complained of pain in both his thighs, knees, hip and lower back. The patient denied any triggering events: heavy lifting, pushing, or pulling. He denied any recent trauma, injury or accident; any fever, chills, night sweats, nausea or vomiting; any bowel/bladder incontinence or saddle anesthesia; any new-onset weakness, tingling or numbness in his extremities. He denied taking any prescription medications or using any illicit drugs. He also denied any family history of autoimmune disorders.

On physical examination, the patient was afebrile and well appearing. The patient was mildly tachycardic. On examining his lower extremities, the patient had pain mainly in his hamstring and thigh muscles, worse on the left. The patient had mild pain in bilateral paraspinal muscles without any significant mid-line vertebral pain. His straight leg raise test was negative. Strength in all muscle groups scored 5 on a scale of 0 to 5 , sensory and motor functions scored 5 on a scale of 0 to 5 and deep tendon reflexes were normal. The patient's lower extremities and skin were warm and well perfused with normal peripheral pulses. Laboratory tests were obtained as listed in Table 1. 


\section{Cureus}

Component

Hematology:

White blood cell count

Red blood cell count

Hemoglobin

Hematocrit

Mean corpuscular volume

Mean corpuscular hemoglobin

Mean corpuscular hemoglobin concentration

Platelet count

Red cell distribution width

Mean platelet volume

Basic metabolic panel:

Sodium

Potassium

Chloride

Carbon dioxide

Calcium

Creatinine

Blood urea nitrogen

Glucose

Estimated glomerular filtration rate, non-African American

Estimated glomerular filtration rate, African American

Anion gap

Inflammatory markers:

Sedimentation rate

C-reactive protein

Creatine kinase, total

Blood culture:

Specimen description

Culture
Reference Range

Day 1

4.0-10.8 kilo per microliter

7.43

4.5-6.1 million per microliter

4.81

14.0-17.0 gram per deciliter

13.1 (low)

42.0-52.0 percentage

39.5 (low)

81-99 femtoliter

82.1

27-33 picogram

27.2

32-36 gram per deciliter

33.2

130-400 kilo per microliter

210

35-46 femtoliter

36.4

9.4-12.4 femtoliter

11.0

137-146 millimole per liter

134 (low)

3.6-5.0 millimole per liter

3.6

98-112 millimole per liter

99

21-32 millimole per liter

28

8.4-10.2 milligram per deciliter

8.7

0.70-1.20 milligram per deciliter

0.90

8-25 milligram per deciliter

16

70-99 milligram per deciliter

94

$>59.9$ milliliter per minute per 1.73 square meter

114

$>59.9$ milliliter per minute per 1.73 square meter

$>120$

3.00-14.00 millimole per liter

7

54 (high)

0-10 millimeter per hour

12.80 (high)

0-1.0 milligram per deciliter

82

\section{TABLE 1: Laboratory Test Results}

The patient was given ketorolac, a nonsteroidal anti-inflammatory drug (NSAID), in addition to intravenous methylprednisolone, providing him moderate symptomatic relief. The patient was discharged home with oral methylprednisolone (Medrol Dosepak) in a stable condition with a clinical diagnosis of myalgia. The patient was ruled out of having polymyositis or rhabdomyolysis in the setting of a normal creatine kinase level, infectious arthritis due to normal white cell count.

The patient followed up at the clinic a few days later, for concerns of migratory polyarthritis. The patient complained of ongoing left hip pain, describing it as sharp in nature and associated with muscle tightness. 


\section{Cureus}

The patient reported intermittent, waxing and waning, but progressively worsening joint pain and stiffness in his lower back and spine, and right shoulder. He rated his pain as 6-8 on a scale of 1 to 10 . The patient also complained of left knee pain with associated mild to moderate swelling, affecting his ability to walk. The patient denied any symptomatic improvement with the Medrol Dosepak prescribed to him in the emergency department. The patient was taking occasional NSAIDs for pain relief, providing him "some” relief. The patient enjoys hiking but denied any recent exposure to ticks. The patient has been sexually active with female partners but denied any new sexual partners in the past few months. The patient denied any past medical history of sexually transmitted diseases. On review of systems, the patient reported subjective low-grade fever without chills, malaise, night sweats or weight loss. He reported mild dysuria in the last one week, without hematuria. The patient had an unremarkable physical examination except for 1+ swelling of his left knee without increased warmth or erythema, and moderately decreased passive range of motion. Under sterile conditions, an injection of a 40-cubic centimeter of Kenalog- 40 was administered in his left knee for pain relief.

Laboratory tests were ordered for antinuclear antibody (ANA) screen, thyroid-stimulating hormone (TSH), rheumatoid factor (RF), anti-cyclic citrulline peptide (anti-CCP) antibody and urinalysis with microscopy; all had normal results. The patient had a negative ANA result as well as normal TSH level at 1.52 microliter per milliliter (normal 0.35-4.94 microliter per milliliter), RF was $<10$ units per milliliter (normal $<15$ units per milliliter) and anti-CCP antibody was 8 millimole per liter (normal 3.00-14.00 millimole per liter) and a normal urinalysis. An x-ray of bilateral knee demonstrated no acute fracture or dislocation. Medial, lateral and patellofemoral compartments were well maintained. No acute osseous findings were noted (Figure 1).

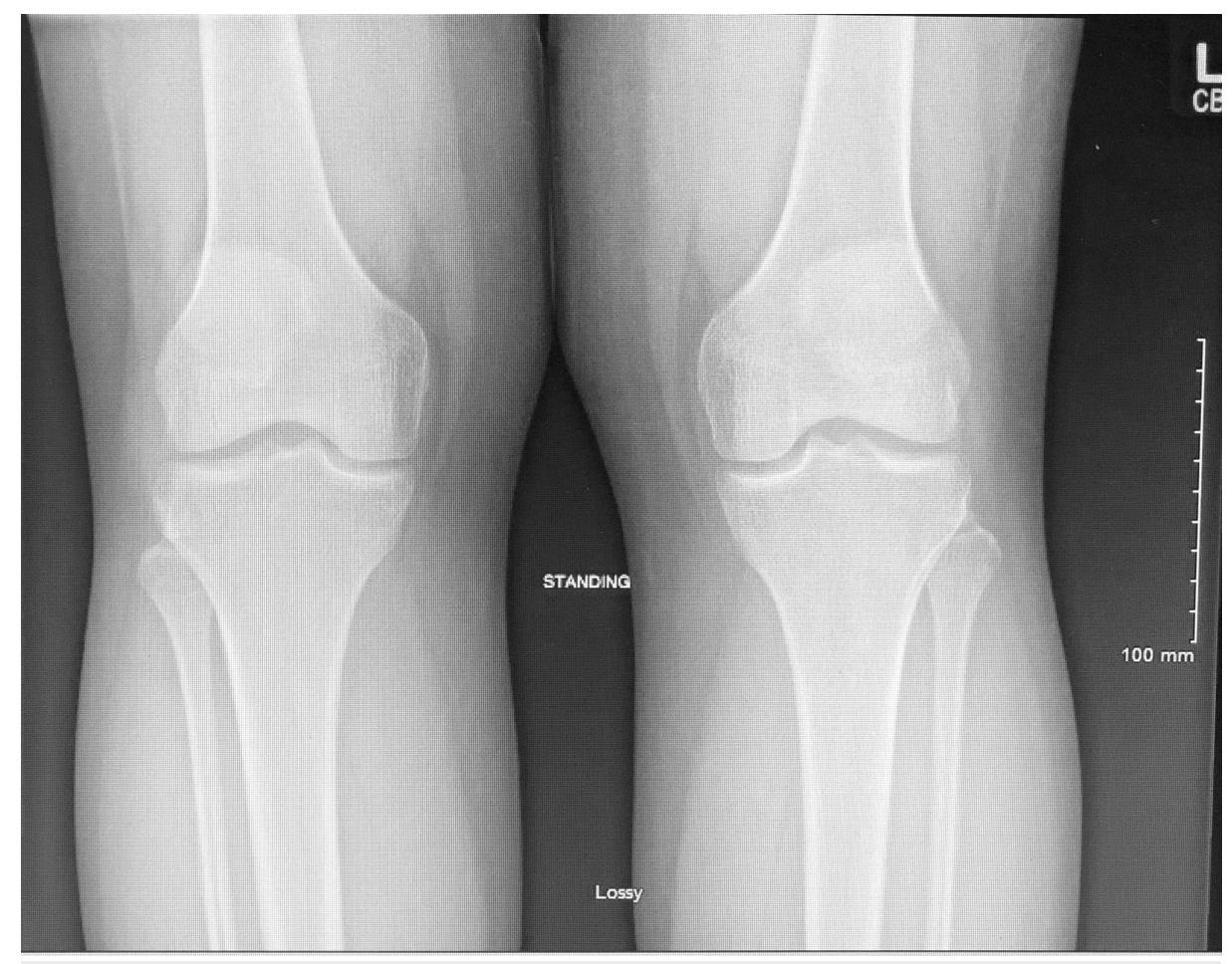

FIGURE 1: X-ray Bilateral Knee in Standing View

The patient was recommended to continue taking ibuprofen $600 \mathrm{mg}$ three times daily with food, regularly for at least 14 days. He was advised to wear a knee brace for support while physically active and elevate his legs while resting. Further laboratory tests were ordered (Table 2). 


\section{Cureus}

\begin{tabular}{|c|c|c|c|}
\hline Diagnostic procedure & Result & Units & Reference range \\
\hline Sedimentation rate & 33 (high) & millimeter per hour & $0-10$ \\
\hline \multicolumn{4}{|l|}{ Hepatitis function panel } \\
\hline Albumin & 3.5 & gram per deciliter & $3.4-5.0$ \\
\hline Total bilirubin & 0.3 & milligram per deciliter & $0.2-1.4$ \\
\hline Bilirubin, direct & $<0.1$ & milligram per deciliter & $0.0-0.2$ \\
\hline Alkaline phosphatase & 109 & units per liter & $38-127$ \\
\hline $\begin{array}{l}\text { Aspartate } \\
\text { aminotransferase/serum } \\
\text { glutamic-oxaloacetic } \\
\text { transaminase }\end{array}$ & 19 & nits per liter & $9-40$ \\
\hline $\begin{array}{l}\text { Alanine } \\
\text { aminotransferase/serum } \\
\text { glutamic-pyruvic } \\
\text { transaminase }\end{array}$ & 50 & nits per liter & $12-64$ \\
\hline Total protein & 8.6 (high) & gram per deciliter & $6.4-8.2$ \\
\hline $\begin{array}{l}\text { Human immunodeficiency } \\
\text { virus } 1 \text { /human } \\
\text { immunodeficiency virus } 2 \\
\text { antibody, protein } 24 \\
\text { antigen }\end{array}$ & $\begin{array}{l}\text { Non- } \\
\text { reactive }\end{array}$ & N/A & Non-reactive \\
\hline
\end{tabular}

Parvovirus B19 antibody, immunoglobulin $\mathrm{G}$ and immunoglobulin $\mathrm{M}$ :

3.7 (high)

Parvovirus immunoglobulin Unit: index value 0.9 index value: negative- no significant level of detectable parvovirus B19 G immunoglobulin $G$ antibody 0.9-1.1 index value: equivocal - repeat testing in 10-14 days may be helpful $>1.1$ index value: positive- immunoglobulin $\mathrm{G}$ antibody to parvovirus B19 detected, which may indicate a current or past infection

0.2

Parvovirus immunoglobulin Unit: index value $<0.9$ index value: negative- no significant level of detectable parvovirus B19 M immunoglobulin $M$ antibody 0.9-1.1 index value: equivocal - repeat testing in 10-14 days may be helpful >1.1 index value: positive- immunoglobulin $\mathrm{M}$ antibody to parvovirus B19 detected, which may indicate a current or past infection reference range: $<0.9$

Chlamydia/Gonorrhea by nucleic acid amplification source: urine

\begin{tabular}{|c|c|c|}
\hline Chlamydia trachomatis & Positive & e State Department of Public Health Reference range: \\
\hline Neisseria gonorrhea & Negative & negativ \\
\hline
\end{tabular}

\section{TABLE 2: Laboratory Test Results}

N/A, not applicable

The patient was informed of the laboratory test results and was started on doxycycline $100 \mathrm{mg}$ twice daily for seven days. The patient was encouraged to contact his sexual partner(s) and recommend treatment. He was advised to avoid sexual activity until the treatment was completed and educated about the importance of using condoms (barrier protection). The State Department of Public Health was contacted and informed.

\section{Discussion}

Reactive arthritis is a relatively rare disease that typically occurs in young adults, affecting both men and women. In a population-based study, the incidence of reactive arthritis following documented enteric bacterial infections ranged from 0.6 to 3.1 cases per 100,000, depending on the organism [3]. The causative pathogens, incidence and prevalence of reactive arthritis depend on the geographic region. In general, 


\section{Cureus}

among the pathogens, Chlamydia is probably the most endemic. A systematic literature review conducted in 2016 identified only three studies of low to moderate quality reporting an incidence of sexually acquired reactive arthritis of 3.0 to 8.1 percentage [4].

The onset of reactive arthritis is usually acute or sporadic. Patients usually develop symptoms two to four weeks from the start of infection to the onset of musculoskeletal symptoms; in Chlamydia infection, the interval can extend up to four weeks. The disease is uncommon in children. Male and female patients are equally at risk for developing reactive arthritis induced by gastrointestinal infection, while male patients are more frequently diagnosed with reactive arthritis triggered by Chlamydia trachomatis infection [5].

Patients have typically asymmetric oligoarthritis, often in large joints of lower extremities. Patients also have arthritis in their upper extremities. Occasionally, a mild polyarticular form of arthritis, particularly in the small joints, can occur. Patients can also have dactylitis (sausage digit). In addition to arthritis, patients can develop bursitis, enthesitis, and tendonitis. Other extra-articular features include inflammatory back pain, eye disease; conjunctivitis (more common), anterior uveitis, skin changes; erythema nodosum, keratoderma blenorrhagicum, and circinate balanitis. Circinate balanitis has most frequently been associated with Chlamydia arthritis.

The diagnosis of reactive arthritis relies on the typical clinical presentation and the triggering infection. During the earlier symptomatic phase of enteric infections, isolation is usually possible from the stools. Hence, the diagnosis of reactive arthritis is often dependent on the detection of specific antibodies in the serum (Tables 3, 4) [5-7].

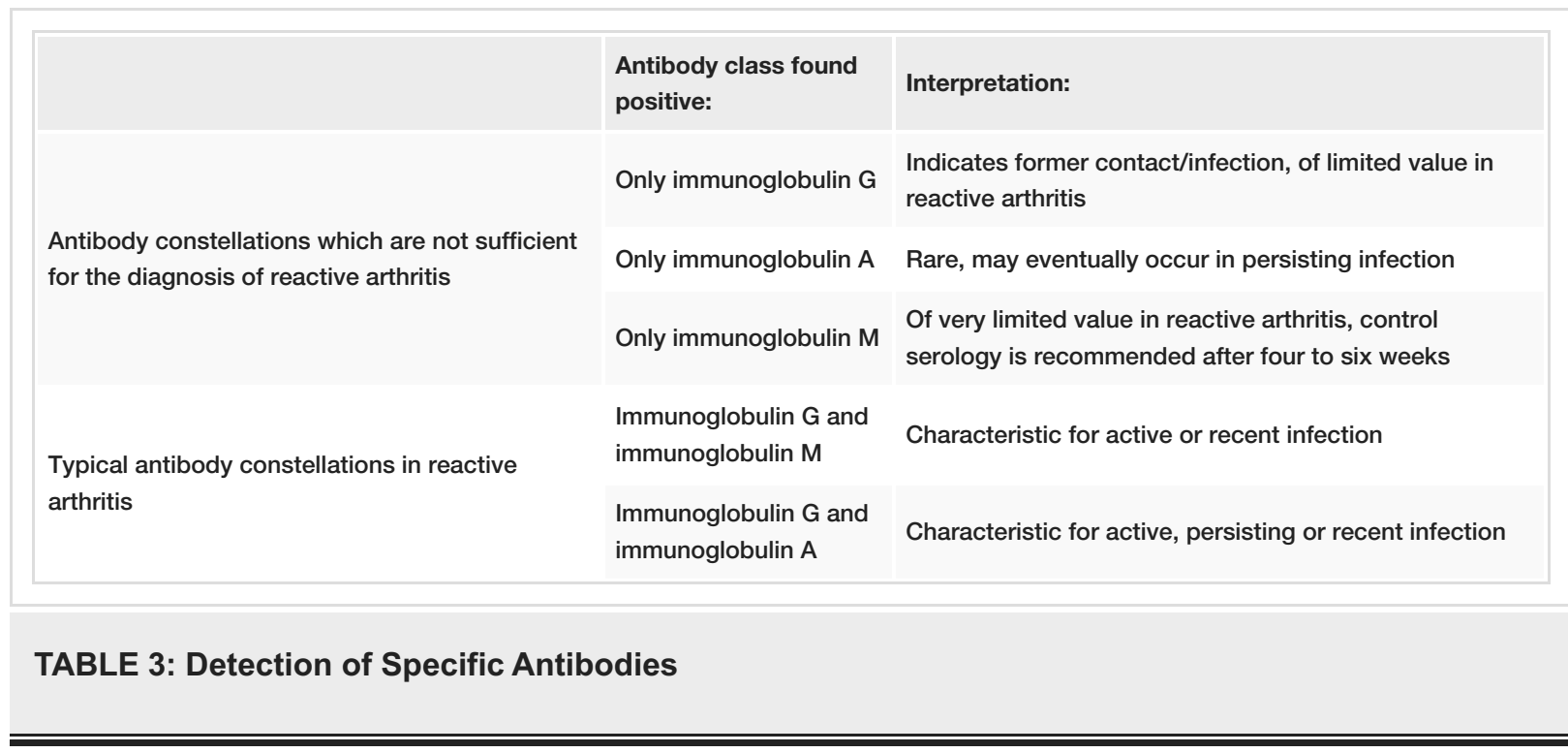




\title{
Cureus
}

\begin{tabular}{|c|c|c|}
\hline Diagnosis & Serology: & Detection of the organism: \\
\hline \multicolumn{3}{|c|}{ Post-urogenital reactive arthritis: } \\
\hline Chlamydia trachomatis & + & Polymerase chain reaction in first-void urine \\
\hline Mycoplasma & - & Culture from urogenital swab \\
\hline \multicolumn{3}{|c|}{ Post-enteric reactive arthritis: } \\
\hline Yersinia & + & Stool culture \\
\hline Salmonella & + & Stool culture \\
\hline Campylobacter & + & Stool culture \\
\hline Shigella & - & Stool culture \\
\hline
\end{tabular}

\section{TABLE 4: Serology to Detect Specific Organisms}

\author{
"+", positive \\ "-", negative
}

Acute-phase reactants like erythrocyte sedimentation rate and/or C-reactive protein may be elevated. However, these may be normal in many patients. Studies have reported 60 to 80 percentage of HLA-B27positive patients with reactive arthritis. Synovial fluid findings are nonspecific and are characteristic of inflammatory arthritis, with elevated leukocyte counts, predominantly neutrophils. Synovial fluid leukocyte count is between 2,000 and 64,000 millions per cubic millimeter [6]. There are no specific findings on plain radiographs that can establish the diagnosis of reactive arthritis. In patients with chronic joint disease, imaging studies such as ultrasonography, scintigraphy (radionuclide bone scanning) or magnetic resonance imaging can also identify changes consistent with peripheral synovitis, enthesitis or sacroiliitis.

Reactive arthritis is a clinical diagnosis based on the pattern of findings and exclusion of other diseases. There is no single definitive diagnostic test, nor are there validated diagnostic criteria.

Acute inflammatory monoarthritis or oligoarthritis may occur in a variety of disorders. The differential diagnosis of reactive arthritis can be guided, in part, by the pattern of symptoms and findings that are associated with arthritis and that may suggest a related infectious or other systemic disorder. The following differential diagnosis should be considered (Table 5). 


\section{Cureus}

\begin{tabular}{|c|c|c|c|}
\hline $\begin{array}{l}\text { Pattern of } \\
\text { symptoms: }\end{array}$ & $\begin{array}{l}\text { Ditferential } \\
\text { diagnosis: }\end{array}$ & Confirmatory test: & Points to note: \\
\hline \multirow{5}{*}{ Monoarthritis } & $\begin{array}{l}\text { Traumatic } \\
\text { arthritis }\end{array}$ & Imaging study example. $x$-ray of the joint & $\begin{array}{l}\text { Inquire about recent history of } \\
\text { trauma or injury }\end{array}$ \\
\hline & Gout & $\begin{array}{l}\text { Serum uric acid level, inflammatory markers, synovial fluid } \\
\text { examination; for crystal study (needle-shaped monosodium } \\
\text { urate crystals which are "negatively birefringent") and cell study }\end{array}$ & $\begin{array}{l}\text { Personal past medical history of } \\
\text { gout, family history of gout }\end{array}$ \\
\hline & $\begin{array}{l}\text { Calcium } \\
\text { pyrophosphate } \\
\text { deposition } \\
\text { disease }\end{array}$ & $\begin{array}{l}\text { Inflammatory markers, synovial fluid examination; for crystal } \\
\text { study (rhomboid or rectangular shaped, "positively } \\
\text { birefringent") and cell study, and imaging study example. x-ray } \\
\text { of the joint suggestive of chondrocalcinosis }\end{array}$ & $\begin{array}{l}\text { Usually seen in the elderly } \\
\text { population }\end{array}$ \\
\hline & Septic arthritis & $\begin{array}{l}\text { Synovial fluid examination (suggestive of leukocytosis, low } \\
\text { glucose level, high protein level), inflammatory markers }\end{array}$ & $\begin{array}{l}\text { History of recent trauma or injury, } \\
\text { cellulitis-like symptoms }\end{array}$ \\
\hline & $\begin{array}{l}\text { Lyme's } \\
\text { disease }\end{array}$ & Lyme disease antibody screen & History of deer tick exposure \\
\hline Oligoarthritis & $\begin{array}{l}\text { Parvovirus } \\
\text { infection }\end{array}$ & Parvovirus serology tests, inflammatory markers & $\begin{array}{l}\text { symptoms/viral syndrome } \\
\text { symptoms }\end{array}$ \\
\hline \multirow{3}{*}{$\begin{array}{l}\text { Diarrhea and } \\
\text { arthritis }\end{array}$} & $\begin{array}{l}\text { Enteroviral } \\
\text { infection }\end{array}$ & $\mathrm{N} / \mathrm{A}$ & Usually self-limited \\
\hline & $\begin{array}{l}\text { Bacterial } \\
\text { infection }\end{array}$ & Stool examination with culture or serology levels & N/A \\
\hline & $\begin{array}{l}\text { Autoimmune } \\
\text { etiology of } \\
\text { diarrhea }\end{array}$ & $\begin{array}{l}\text { Antinuclear antibody screen with cascade, specific antibody } \\
\text { screen, biopsy or culture }\end{array}$ & $\begin{array}{l}\text { Detailed history of symptoms, } \\
\text { disease-specific antibody screen }\end{array}$ \\
\hline $\begin{array}{l}\text { Genitourinary } \\
\text { symptoms } \\
\text { and arthritis }\end{array}$ & $\begin{array}{l}\text { Disseminated } \\
\text { gonococcal } \\
\text { infection } \\
\text { Chlamydia } \\
\text { trachomatis }\end{array}$ & $\begin{array}{l}\text { Urethral or cervical swabs, urinary gonococcal and chlamydial } \\
\text { screen, nucleic acid amplification test, synovial fluid } \\
\text { examination }\end{array}$ & $\begin{array}{l}\text { Detailed history of urinary tract } \\
\text { infection symptoms, past medical } \\
\text { history of sexually transmitted } \\
\text { diseases, sexual history }\end{array}$ \\
\hline
\end{tabular}

TABLE 5: Differential Diagnosis

N/A, not applicable

The management of the patient depends on the triggering factor contributing to their symptoms. Hence, there are several major aspects of its management. Antibiotics are not used to treat arthritis specifically; however, it may be indicated for the treatment of the underlying infection if there is evidence of ongoing genitourinary infection or gastrointestinal infection or carriage of potentially pathogenic organisms. In patients with chronic reactive arthritis induced by enteric bacteria, the available evidence does not support the use of long-term antibiotics $[8,9]$. The main objectives of therapeutic management in a patient with reactive arthritis are patient education and pain relief to facilitate physical therapy. Educating the patient regarding the good prognosis is of utmost importance, to resolve their fears of serious physical impairment in the future.

Antibiotic use to treat new urogenital tract infections can substantially decrease the risk of reactive arthritis . Chlamydia trachomatis and Neisseria gonorrhea are venereal diseases; hence, treatment is of utmost value even in the absence of arthritis. Chlamydia trachomatis is treated with azithromycin ( $1 \mathrm{~g}$ orally as a single dose) or doxycycline (100 mg twice daily for seven days). The patient's sexual partner(s) should simultaneously be treated to prevent reinfection. Neisseria gonorrhea should be treated with a single dose of $250 \mathrm{mg}$ of intramuscular ceftriaxone and $1 \mathrm{~g}$ of oral azithromycin. There are no data to show that treatment of diarrhea with antibiotics has an impact on possible subsequent arthritis, and such treatment is therefore not recommended [7]. Controlled studies have shown no beneficial effects favoring the prolonged long-term use of antibiotics for the treatment of reactive arthritis except lymecycline showed to reduce the duration of Chlamydia-induced arthritis in a one-year study. This promising result was not confirmed either in two subsequent studies using tetracycline or in other trials comparing ciprofloxacin or azithromycin with 
placebo [7].

To treat acute arthritis, the use of non-steroidal anti-inflammatory drugs, often in high dose, is usually of major benefit. Intra-articular glucocorticoid injections can be administered if the patient has mono- or oligoarticular joint disease. Enthesopathy responds to local glucocorticoid injections.

Systemic glucocorticoids are indicated in patients with severe polyarthritis, high systemic inflammation, febrile patient or patient with symptoms of carditis or atrioventricular conduction disturbance. The starting dose of prednisone/prednisolone is usually 20-40 milligram per day [5]. If symptoms persist beyond three to six months, the use of disease-modifying anti-rheumatic drugs such as sulfasalazine, methotrexate or tumor necrosis factor alpha inhibitors may be necessary for symptom control and to prevent joint erosion. Therapy is discontinued three to six months following disease remission.

The course of reactive arthritis is variable, depending upon the triggering pathogen and the genetic background of the host. The typical disease duration is three to five months. Most patients either remit completely or have little active disease within six to 12 months after presentation, but $15 \%$ to $20 \%$ may experience more chronic persistent arthritis. After entering remission of peripheral joint arthritis, pain is occasionally still noted in the joints, at enthesitis or in the spine [5, 6].

\section{Conclusions}

Reactive arthritis has been defined by consensus as a form of arthritis that is associated with a coexisting or recent antecedent extra-articular infection. It thus represents an excellent example for acquiring a detailed history of presenting illness, past medical history, social and family history, and understanding pathophysiology, improving diagnosis, and developing etiology-based treatment strategies. The goal of treatment for reactive arthritis is to treat the underlying cause of symptoms, eliminate the causative organism persisting in the host, and provide patient symptomatic relief.

\section{Additional Information \\ Disclosures}

Human subjects: Consent was obtained by all participants in this study. Conflicts of interest: In compliance with the ICMJE uniform disclosure form, all authors declare the following: Payment/services info: All authors have declared that no financial support was received from any organization for the submitted work. Financial relationships: All authors have declared that they have no financial relationships at present or within the previous three years with any organizations that might have an interest in the submitted work. Other relationships: All authors have declared that there are no other relationships or activities that could appear to have influenced the submitted work.

\section{References}

1. Ahvonen P, Sievers K, Aho K: Arthritis associated with Yersinia enterocolitica infection. Acta Rheumatol Scand. 1969, 15:232-253. 10.3109/rhe1.1969.15.issue-1-4.32

2. Braun J, Kingsley G, van der Heijde D, Sieper J: On the difficulties of establishing a consensus on the definition of and diagnostic investigations for reactive arthritis. Results and discussion of a questionnaire prepared for the 4th International Workshop on Reactive Arthritis Berlin, Germany, July 3-6,1999. J Rheumatol. 2000, 27:2185-2192.

3. Townes JM: Reactive arthritis after enteric infections in the United States: the problem of definition . Clin Infect Dis. 2010, 50:247-254. 10.1086/649540

4. Denison HJ, Curtis EM, Clynes MA, Bromhead C, Dennison EM, Grainger R: The incidence of sexually acquired reactive arthritis: a systematic literature review. Clin Rheumatol. 2016, 35:2639-2648. 10.1007/s10067-016-3364-0

5. Hannu T: Reactive arthritis. Best Pract Res Clin Rheumatol. 2011, 25:347-357. 10.1016/j.berh.2011.01.018

6. Hannu T, Inman R, Granfors K, Leirisalo-Repo M: Reactive arthritis or post-infectious arthritis? . Best Pract Res Clin Rheumatol. 2006, 20:419-16777574. 10.1016/j.berh.2006.02.003

7. Rihl M, Klos A, Köhler L, Kuipers JG: Infection and musculoskeletal conditions: reactive arthritis . Best Pract Res Clin Rheumatol. 2006, 20:1119-1137. 10.1016/j.berh.2006.08.008

8. Leirisalo-Repo M: Reactive arthritis. Scand J Rheumatol. 2005, 34:251-259. 10.1080/03009740500202540

9. Lauhio A, Leirisalo-Repo M, Lähdevirta J, Saikku P, Repo H: Double-blind, placebo-controlled study of three-month treatment with lymecycline in reactive arthritis, with special reference to Chlamydia arthritis. Arthritis Rheum. 1991, 34:6-14. 10.1002/art.1780340103 